\title{
O PENSAMENTO FILOGENÉTICO NO ENSINO FUNDAMENTAL II: RELATO DE UMA ATIVIDADE LÚDICO-METAFÓRICA
}

\author{
Marcela D’Ambrosio ${ }^{1}$ \\ Marina Reiter ${ }^{2}$ \\ Fernando Santiago dos Santos ${ }^{3}$
}

\section{Introdução}

A representação gráfica mais direta e difundida do processo evolutivo é uma árvore filogenética. A ciência que estuda e reconstrói tais árvores é chamada de sistemática filogenética e tem como principal objetivo descobrir os graus de parentesco dentro de um grupo de organismos (HENNIG, 1965). O termo "pensamento filogenético" foi cunhado para descrever a habilidade de visualizar relações evolutivas de parentesco na abstração de tais árvores (MEISEL, 2010). De acordo com Gregory (2008), a aquisição de habilidades no pensamento filogenético é ainda um desafio e um componente educacional crítico e, ao mesmo tempo, uma imagem comumente encontrada nas diversas mídias e livros didáticos.

$\mathrm{Na}$ literatura acadêmica, existem várias propostas metodológicas de como ensinar filogenia para graduandos de Ciências Biológicas (PERRY et al., 2008; MEISEL, 2010, entre outros), todas demonstrando que a "alfabetização filogenética" é possível baseando-se na compreensão de conceitos ao invés da memorização da terminologia. Outro aspecto importante analisado por esses artigos é a presença de erros conceituais na interpretação e entendimento de árvores filogenéticas, o que indica a importância da sua abordagem em sala de aula.

O presente trabalho é um relato de experiência baseado em uma atividade de intervenção realizada em uma escola privada da cidade de Campinas - SP, no contexto de uma disciplina de estágio supervisionado de um curso de licenciatura em Ciências Biológicas. Nessa escola, o assunto biodiversidade fazia parte do conteúdo programático do sétimo ano do Ensino Fundamental II, e, portanto, esse foi o ano escolhido para a realização da intervenção. Para a elaboração deste relato, foram utilizados o diário de campo da estagiária e a atividade escrita feita pelos estudantes.

\section{A atividade}

Para abordar o pensamento filogenético com os estudantes, optou-se por desenvolver uma atividade chamada "A Grande Corrida dos Clados" (GOLDSMITH, 2003), a qual desenvolve o raciocínio necessário para a interpretação de árvores de uma maneira metafórica, sem abordar os conceitos e a nomenclatura específicos da área.

A atividade permitiu a participação direta e ativa dos estudantes e também trabalhou com seu imaginário. Imagens são de suma importância na representação, na construção e na comunicação de ideias e conceitos científicos (GOUVÊA et al., 2001), não podendo ser menosprezadas no ensino de Ciências. Além de permitir organizar a biodiversidade, as árvores filogenéticas são uma imagem narrativa. Contam uma história de descendência com modificação e ancestralidade comum entre todos os seres vivos. Para sua reconstrução, deve-se inferir as relações de parentesco entre os taxa, analisando-se características compartilhadas entre os grupos.

\footnotetext{
${ }^{1}$ Universidade Estadual de Campinas.

${ }^{2}$ Escola do Sítio, Campinas - SP.

${ }^{3}$ Instituto Federal de Educação, Ciência e Tecnologia de São Paulo, câmpus São Roque
} 
Os estudantes foram divididos em grupos de seis alunos e cada grupo recebeu um conjunto de seis cartões estampados com diferentes figuras (Figura 1). Eles deveriam imaginar uma corrida por uma floresta com seis corredores que iniciavam a corrida num mesmo ponto, mas conforme percorriam a "pista de corrida" apareciam bifurcações e cada corredor poderia escolher qual das duas opções de caminho percorrer. Ao longo da corrida, os corredores que haviam recebido um cartão em branco deveriam coletar carimbos em estações espalhadas pelo caminho. No final, cada corredor chegava a um ponto de corrida diferente, com um cartão com carimbos diferentes. $\mathrm{O}$ desafio dos estudantes era reconstruir o mapa da corrida, com suas ramificações, suas estações e os seis pontos de chegada a partir das cartas dos corredores (GOLDSMITH, 2003).

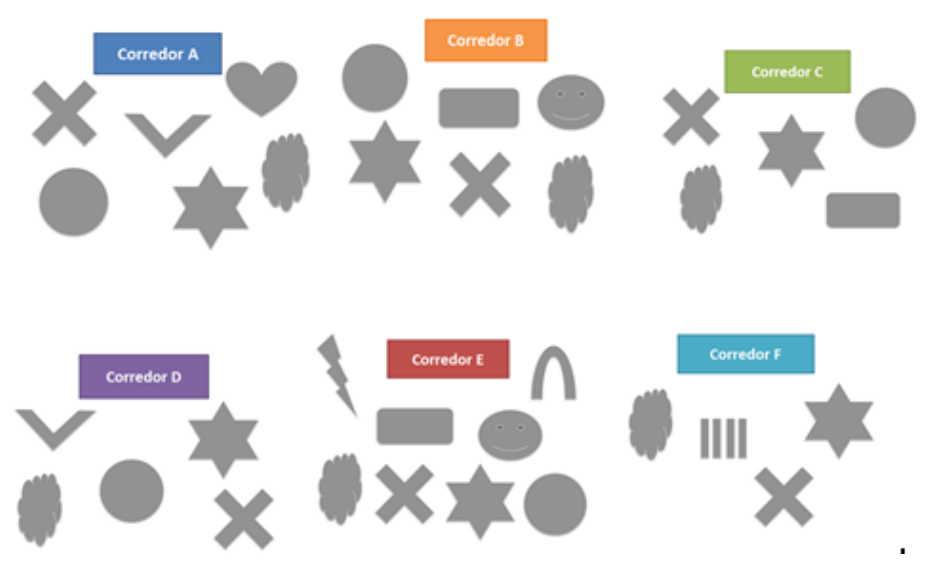

Figura 1. Cartões utilizados na atividade. Cada grupo recebeu as seis cartas e trabalhou a partir das figuras nelas representadas. Fonte: Goldsmith (2003).

Ao invés de reconstruir o mapa diretamente numa folha de papel, os alunos fizeram a reconstrução no chão da quadra coberta da escola (Figura 2). Eles receberam também os carimbos impressos separadamente para irem marcando as estações e depois passaram o mapa construído para uma folha de papel (Figura 3).

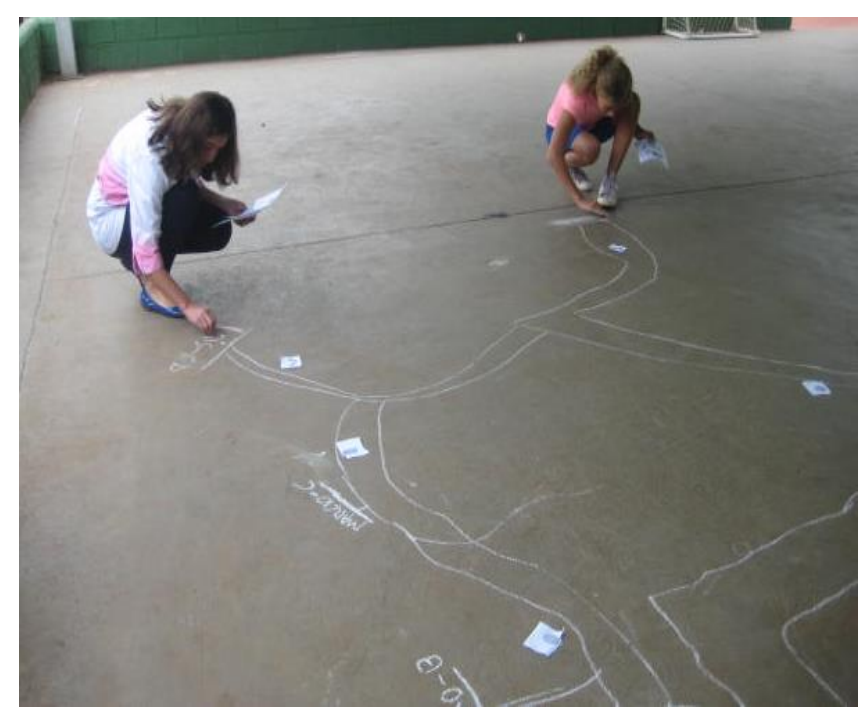

Figura 2. Mapa desenhado por um dos grupos na atividade "A Grande Corrida dos Clados". 
A princípio, a atividade pareceu difícil aos estudantes, motivo pelo qual foram instruídos a olhar os carimbos em comum e entender que a estação correspondente ao carimbo que todos os corredores tinham em seus cartões estaria antes da primeira bifurcação da pista de corrida e, assim por diante. Uma vez compreendida a lógica da atividade, todos os grupos conseguiram completá-la com êxito. Alguns cuidados tiveram de ser tomados, como a noção de que os corredores representavam linhagens e não uma espécie ou um organismo em si, e foram discutidos pela estagiária com os estudantes. Os estudantes conseguiram perceber outros aspectos sozinhos, como o fato de que os carimbos representavam características, que o ponto de partida é um momento do passado, no qual viveu o ancestral comum a todos os grupos, enquanto que os pontos de chegada representam um momento presente.

Um aspecto importante percebido com a atividade é que os diferentes grupos desenharam as estações bifurcando ou para direita ou para esquerda, sendo ambas corretas e representando a rotação de nodos de um cladograma, habilidade importante no pensamento filogenético (GREGORY, 2008). Os alunos puderam perceber, desta forma, que o importante não era o local exato aonde cada corredor chegava, mas sim a ordem de ramificação do mapa. Um dos grupos, por exemplo, quando solicitado a comparar os mapas de todos os grupos, escreveu: "O jeito de desenhar o mapa é diferente, mas os caminhos que os corredores percorrem são iguais".

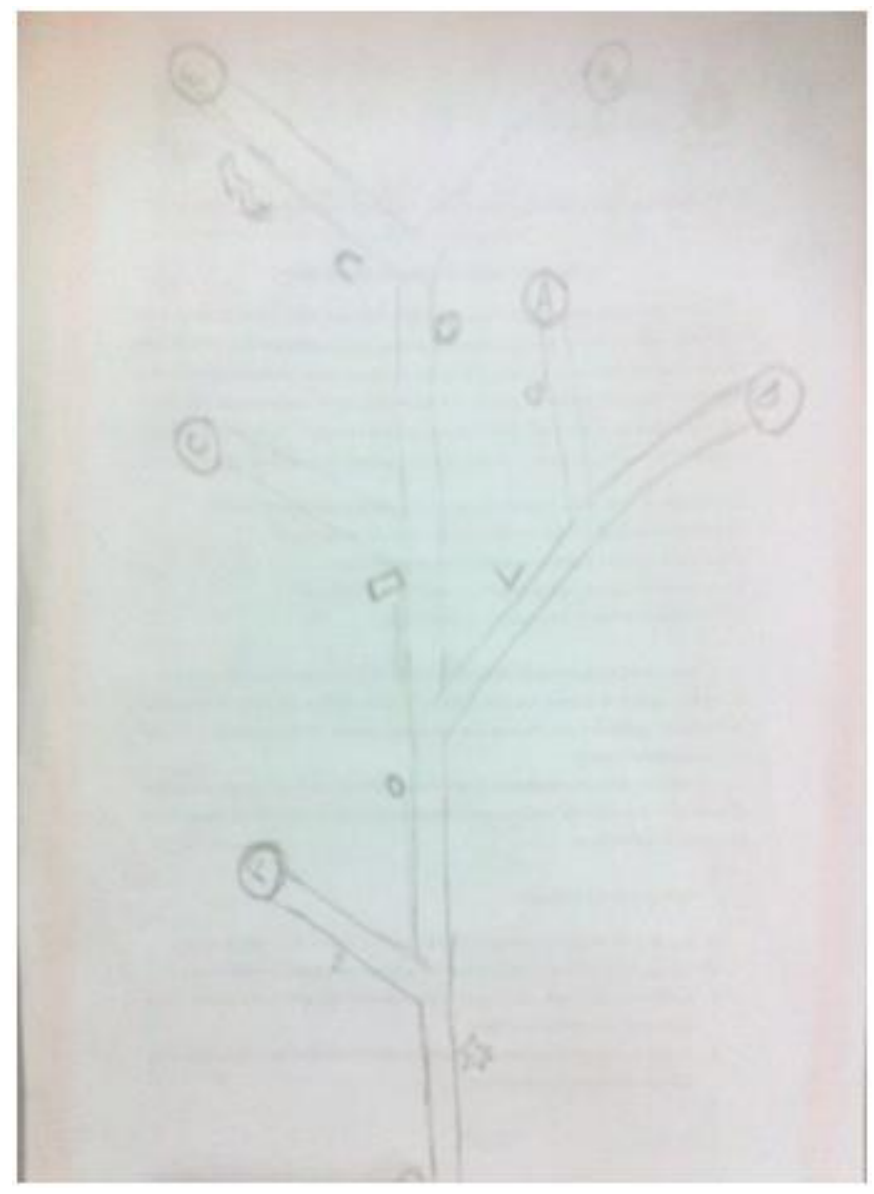

Figura 3. Exemplo de mapa reconstruído por um dos grupos.

Após a finalização da atividade, foi feita uma discussão com os estudantes sobre o significado evolutivo das imagens construídas por eles. Foi abordado o significado de "mudança" da evolução, não sendo esta necessariamente uma melhoria. Foi discutido como o "tempo" era representado e o que são ancestrais comuns. Outro aspecto abordado foi que uma 
espécie vivente hoje não pode ser considerada ancestral de uma espécie que é também vivente. Por fim, a evolução dos grandes primatas foi utilizada para exemplificação, trazendo à tona, também, o significado evolutivo da classificação hierárquica (que já havia sido abordado em aulas anteriores).

\section{Considerações finais}

Embora "A Grande Corrida dos Clados" não tenha sido pensada para o Ensino Fundamental, a transposição foi possível e os resultados foram muito positivos. Os estudantes não desenharam os mapas na forma de um cladograma, mas a lógica aplicada foi a mesma e a correlação para a biologia pode ser feita da mesma forma. $\mathrm{O}$ fato de eles não terem associado a atividade com evolução, em princípio, não foi considerada um problema, principalmente porque era um assunto que eles não haviam estudado ainda. No entanto, eles acompanharam o raciocínio proposto, sempre respondendo às perguntas, trazendo também novas questões e participando de forma ativa; ademais, posteriormente interpretaram de forma correta a representação das árvores filogenéticas, frequentes nos livros didáticos adotados pela escola. Por fim, o ensino de evolução, mesmo sendo o elemento unificador da biologia (DOBZHANSKY, 1973; MEC, 2016), no Ensino Fundamental deve ter suas possibilidades mais bem exploradas, sendo o pensamento filogenético uma ferramenta de grande potencialidade para esse fim.

\section{Referências}

DOBZHANSKY, T. Nothing in biology makes sense except in the light of evolution. The American Biology Teacher, v. 35, p. 125-129, 1973. Disponível em: 〈http://doi.org/10.2307/4444260>.

GOLDISMITH, D.W. Presenting Cladistic Thinking to biology Major \& General Science Students. The American Biology Teacher, v. 65, p. 679-682, 2003.

GOUVÊA, G; MARTINS, I. Imagens e educação em ciências. In: ALVES, N.; SGARBI, P. Espaços e imagens na escola. Rio de Janeiro: Editora DP\&A, 2001.

GREGORY, T.R. Understand Evolutionary Trees. Evo Edu Outreach, v. 1, p. 121-137, 2008.

HENNIG, W. Phylogenetic Systematics. Annual Review of Entomology, v. 10, p. 97-116, 1965.

MEC (MINISTÉRIO DA EDUCAÇÃO). Base Nacional Comum Curricular: Proposta preliminar: segunda versão. Brasília: Conselho Nacional de Secretários de Educação, 2016.

MEISEL, R. P. Teaching Tree-Thinking to Undergraduate Biology Students. Evo Edu Outreach, v. 3, p. 621-628, 2010.

PERRY, J. et al. Evaluating two approaches to help college students understand evolutionary trees through diagramming tasks. CBE Life Sci Educ, v. 7, p. 193-201, 2008. 


\section{Sobre os autores}

Marcela D’Ambrosio é mestranda do Programa de Pós-Graduação em Ensino de Ciências e Matemática Multiunidades da Universidade Estadual de Campinas. É bolsista Capes DS.

E-mail: marceladambrosio@gmail.com.

Marina Reiter é mestre em Ecologia pela Universidade Estadual de Campinas e Professora da Escola do Sítio, Campinas - SP.

E-mail: marinareiter@gmail.com.

Fernando Santiago dos Santos é professor efetivo doutor do Instituto Federal de Educação, Ciência e Tecnologia de São Paulo, câmpus São Roque e Professor Colaborador Visitante da Universidade Estadual de Campinas (Programa de Ensino de Ciências e Matemática Multiunidades/Faculdade de Educação).

E-mail: fernandoss@ifsp.edu.br. 